

\section{Geologic Time}

- the Alge of the Eouth

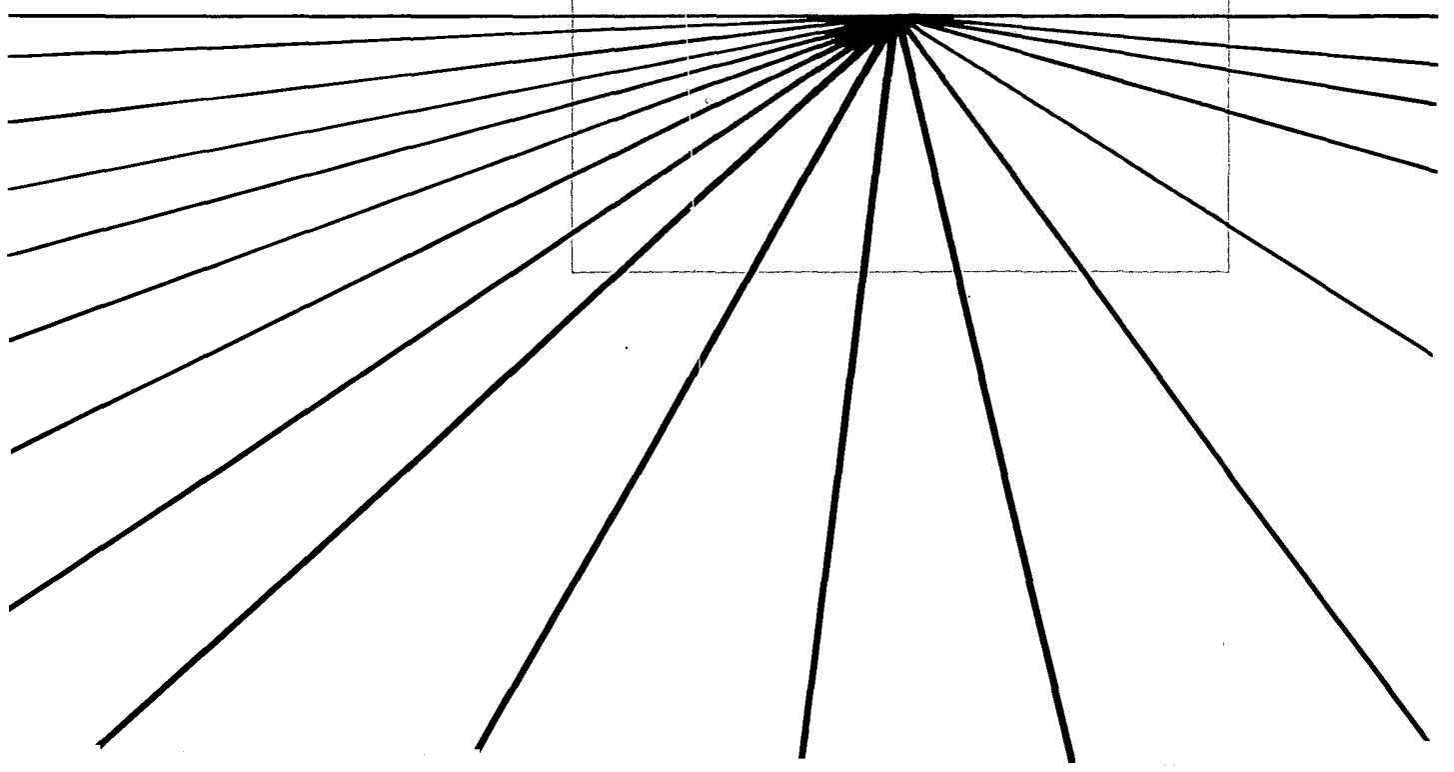


others are tattered, torn, and difficult to decipher. But enough are preserved to reward the reader with accounts of astounding episodes which certify that the Earth is many millions of years old.

Two scales are used to date these episodes and to measure the age of the Earth: a relative time scale, based on the sequence of layering of the rocks, and an atomic time scale, based on the natural radioactivity of chemical elements in some of the rocks. An explanation of the relative scale highlights events in the growth of geologic science itself; the atomic scale is a recent development borrowed from the physical sciences and applied to geologic problems.

\section{THE RELATIVE TIME SCALE}

At the close of the 18th century, the haze of fantasy and mysticism that tended to obscure the true nature of the Earth was being swept away. Careful studies by scientists showed that rocks had diverse origins. Some rock layers, containing clearly identifiable fossil remains of fish and other forms of aquatic animal and plant life, originally formed in the ocean. Other layers, consisting of sand grains winnowed clean by the pounding surf, obviously formed as beach deposits that marked the shorelines of ancient seas. Certain layers are in the form of sand bars and gravel banks-rock debris spread over the land by streams. Some rocks were once lava flows or beds of cinders and ash thrown out of ancient volcanoes; others are portions of large masses of once-molten rock that cooled very slowly far beneath the Earth's surface. Other rocks were so transformed by heat and pressure during the heaving and buckling of the Earth's crust in periods of mountain building that their original features were obliterated.

Between the years of 1785 and 1800 , James Hutton and William Smith advanced the concept of geologic time and strengthened the belief in an ancient world. Hutton, a Scottish geologist, first proposed formally the fundamental principle used to classify rocks according to their relative ages. He concluded, after studying rocks at many outcrops, that each layer represented a specific interval of geologic time. Further, he proposed that wherever uncontorted layers were exposed, the bottom layer was deposited first and was, therefore, the oldest layer exposed; each succeeding layer, up to the topmost one, was progressively younger.

Today, such a proposal appears to be quite elementary but, nearly 200 years ago, it amounted to a major breakthrough in 
scientific reasoning by establishing a rational basis for relative time measurements. However, unlike tree-ring dating - in which each ring is a measure of 1 year's growth-no precise rate of deposition can be determined for most of the rock layers. Therefore, the actual length of geologic time represented by any given layer is usually unknown or, at best, a matter of opinion.

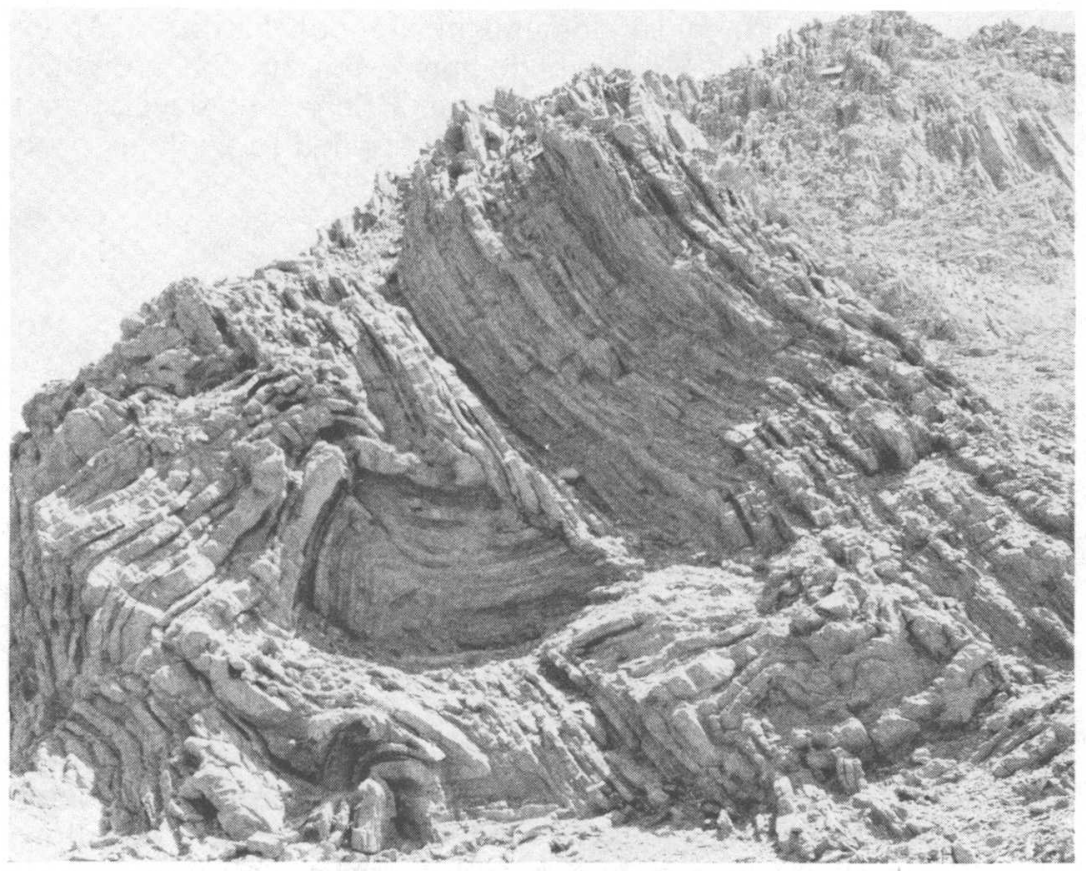

In places where layers of rocks are contorted, the relative ages of the layers may be difficult to determine. View near Copiapo, Chile.

William "Strata" Smith, a civil engineer and surveyor, was well acquainted with areas in southern England where "limestone and shales are layered like slices of bread and butter." His hobby of collecting and cataloging fossil shells from these rocks led to the discovery that certain layers contained fossils unlike those in other layers. Using these key or index fossils as markers, Smith could identify a particular layer of rock wherever it was exposed. Because fossils actually record the slow but progressive development of life, scientists use them to identify rocks of the same age throughout the world.

From the results of studies on the origins of the various kinds of rocks (petrology), coupled with studies of rock layering (stratigraphy) and the evolution of life (paleontology), geologists reconstruct the sequence of events that has shaped the Earth's surface. Their studies show, for example, that during a particular episode the land surface was raised in one part of the world to form high plateaus and mountain ranges. After the uplift of the land, the forces of 


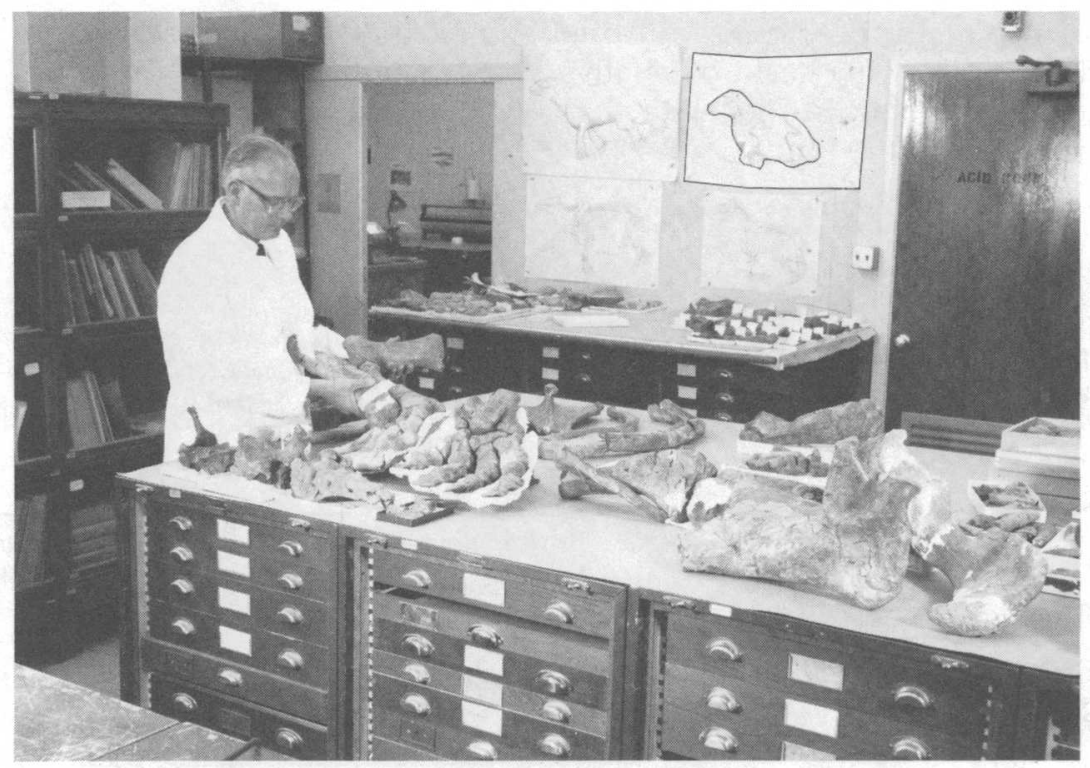

A paleontologist of the U. S. Geological Survey examining the fossil bones of Paleoparadoxia, an aquatic mammal that lived about 14 million years ago.

erosion attacked the highlands and the eroded rock debris was transported and redeposited in the lowlands. During the same interval of time in another part of the world, the land surface subsided and was covered by the seas. With the sinking of the land surface, sediments were deposited on the ocean floor. The evidence for the pre-existence of ancient mountain ranges lies in the nature of the eroded rock debris, and the evidence of the seas' former presence is, in part, the fossil forms of marine life that accumulated with the bottom sediments.

Such recurring events as mountain building and sea encroachment, of which the rocks themselves are records, comprise units of geologic time even though the actual dates of the events are unknown. By comparison, the history of mankind is similarly organized into relative units of time. We speak of human events as occurring either B.C. or A.D.-broad divisions of time. Shorter spans are measured by the dynasties of ancient Egypt or by the reigns of kings and queens in Europe. Geologists have done the same thing to geologic time by dividing the Earth's history into Eras -broad spans based on the general character of life that existed during these times, and Periods-shorter spans based partly on evidence of major disturbances of the Earth's crust.

The names used to designate the divisions of geologic time are a fascinating mixture of words that mark highlights in the historical development of geologic science over the past 200 years. Nearly every name signifies the acceptance of a new scientific concept-a new rung in the ladder of geologic knowledge. 
The major divisions, with brief explanations of each, are shown in the following scale of relative geologic time, which is arranged in chronological order with the oldest division at the bottom, the youngest at the top.

\section{MAJOR DIVISIONS of GEOLOGIC TIME}

\section{CENOZOIC ERA}

(Age of Recent Life)

MESOZOIC ERA

(Age of Medieval Life)

\section{PALEOZOIC ERA}

(Age of Ancient Life)

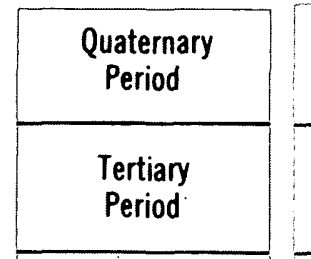

The several geologic eras were originally named Primary, Secondary, Tertiary, and Quaternary. The first two names are no longer used; Tertiary and Quaternary have been retained but used as period designations.

Derived from Latin word for chalk (creta) and first applied to extensive deposits that form white cliffs along the English Channel.

Named for the Jura Mountains, located between France and Switzerland, where rocks of this age were first studied.

Taken from word "trias" in recognition of the threefold character of these rocks in Europe.

Named after the province of Perm, U.S.S.R., where these rocks were first studied.

Named for the State of Pennsylvania where these rocks have produced much coal.

Named for the Mississippi River valley where these rocks are well exposed.

Named after Devonshire England, where these rocks were first studied.

\begin{tabular}{c} 
Devonian \\
Period \\
\hline $\begin{array}{c}\text { Silurian } \\
\text { Period }\end{array}$ \\
\hline $\begin{array}{c}\text { Ordovician } \\
\text { Period }\end{array}$ \\
\hline $\begin{array}{c}\text { Cambrian } \\
\text { Period }\end{array}$ \\
\hline-
\end{tabular}

- Named after Celtic tribes, the Silures and the Ordovices, that lived in Wales during the Roman Conquest.

Taken from Roman name for Wales (Cambria) where rocks containing the earliest evidence of complex forms of life were first studied.

The time between the birth of the planet and the appearance of complex forms of life. More than 80 percent of the Earth's estimated $4 \frac{1}{2}$ billion years falls within this era. 
Keyed to the relative time scale are examples of index fossils, the forms of life which existed during limited periods of geologic time and thus are used as guides to the age of the rocks in which they are preserved.

\section{INDEX FOSSILS}

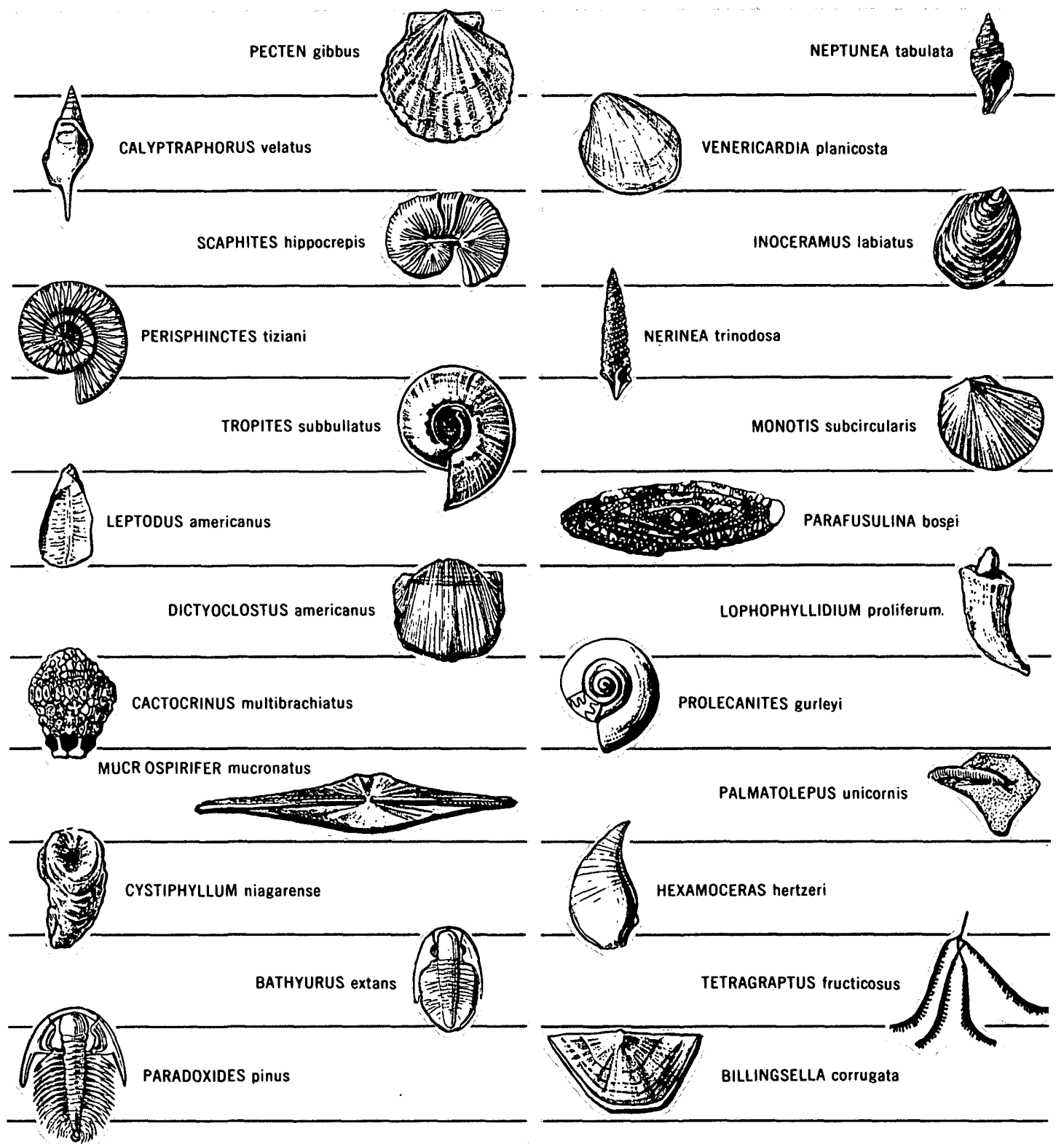


The following examples show how the rock layers themselves are used as a relative time scale:

\section{CORRELATION OF ROCK UNITS WITHIN A SMALL AREA}

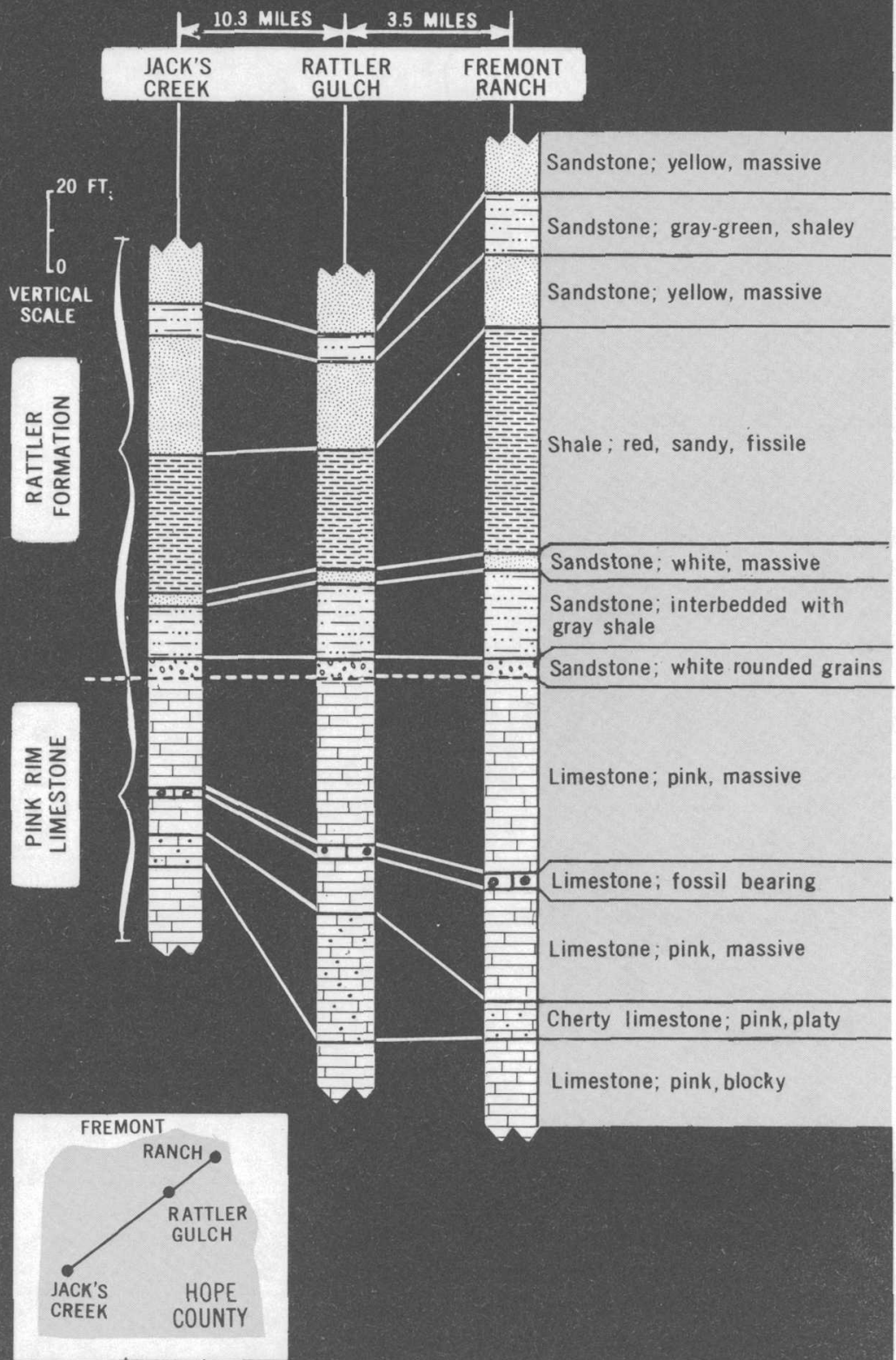


The first diagram (page 8) correlates or matches rock units from three localities within a small area by means of geologic sections compiled from results of field studies.

These sections are typical of the ones geologists prepare when studying the relationships of layers of rocks (beds) throughout a region. Each column represents the sequence of beds at a specific locality. The same beds, which in places may thicken or thin (some may pinch out entirely) according to the local environment of deposition, are bracketed within the lines connecting the three columns.

For convenience, geologists commonly group adjoining beds that possess similar or related features (including fossils) into a single, more conspicuous unit called a formation. The component beds of each formation are described, the formation is named, and the information is published for the use of all geologists. Formation names comprise two words, the first one usually taken from a geographic feature near which the rocks are prominently displayed. The second word indicates the principal rock type, or if of mixed rock types, the word formation is used: The Morrison Formation-the Wingate Sandstone-the Todilto Limestone-the Mancos Shale.

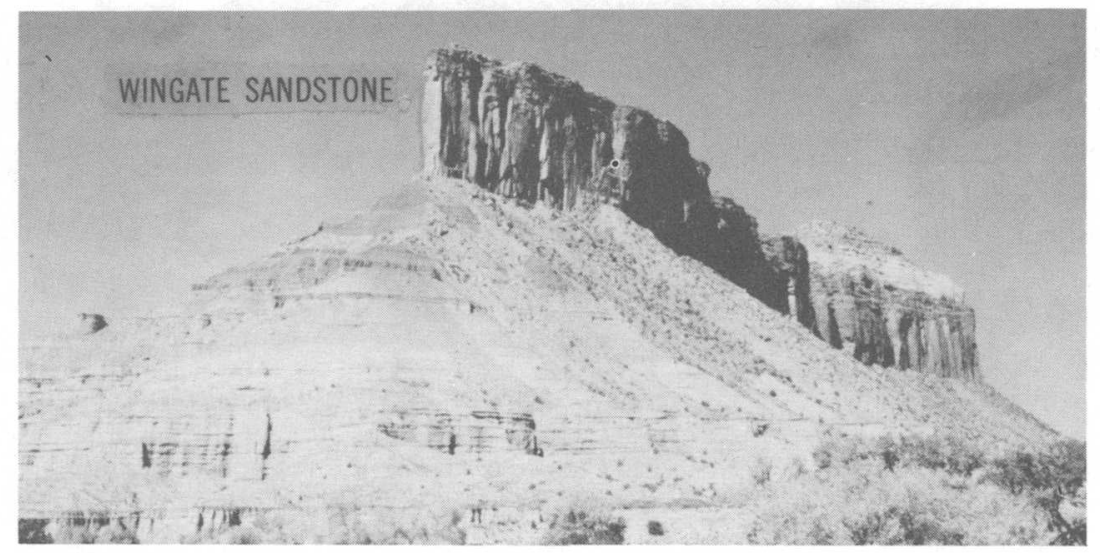

The Wingate Sandstone is a reddish-brown formation consisting largely of windblown sand believed to have accumulated as desert dunes in the Four Corners region of the Southwestern United States about 200 million years ago. Erosion of this formation commonly produces vertical cliffs. View near Gateway, Colorado.

The second diagram (page 10-11) is a composite geologic section, greatly simplified. This example correlates formations throughout a large region in the southwestern part of the United States noted for its spectacular scenery. The composite section can be thought of as representing a large, although incomplete, segment of relative geologic time. A global time scale has been derived by extending the correlations from one place to another and reaching from one continent to another. These correlations are based in large part on fossil evidence. 


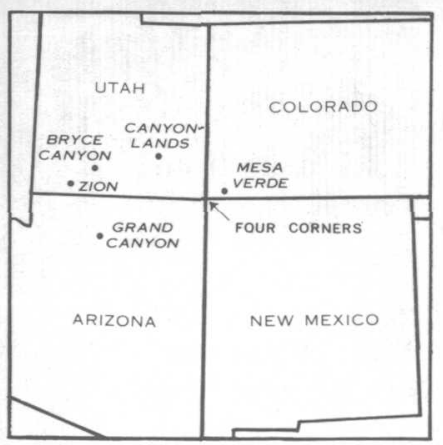

GRAND CANYON NATIONAL PARK ARIZONA
ZION

NATIONAL PARK UTAH

TERTIARY PERIOD

CRETACEOUS PERIOD

JURASSIC PERIOD

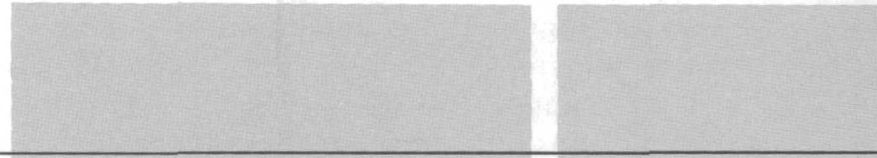

TRIASSIC PERIOD

PERMIAN PERIOD

Kaibab Ls

Toroweap $\mathrm{Fm} \rightarrow$

Coconino Ss

Hermit Shale

Carmel $\mathrm{Fm} \longrightarrow$

Navajo Ss

Kayenta $\mathrm{Fm} \rightarrow$

Wingate Ss

Chinle Fm Moenkopi Fm

Kaibab Ls

Older rocks not exposed

PENNSYLVANIAN PERIOD

MISSISSIPPIAN PERIOD

DEVONIAN PERIOD *

$+$
CAMBRIAN PERIOD

\section{PRECAMBRIAN ERA}

* Rocks of Ordovician and Silurian age are not present in the Grand Canyon. 


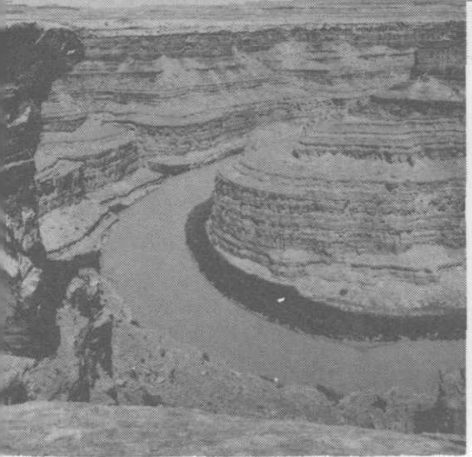

CANYONLANDS NATIONAL PARK UTAH

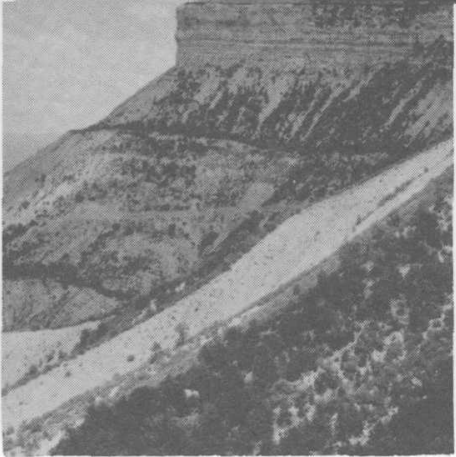

MESA VERDE NATIONAL PARK COLORADO

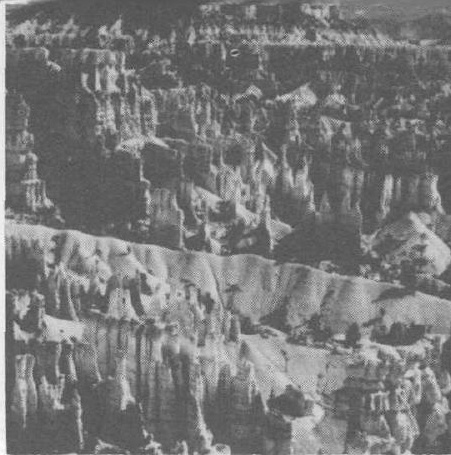

BRYCE CANYON NATIONAL PARK UTAH

Wasatch Fm

Morrison Fm




\section{THE ATOMIC TIME SCALE}

The discovery of the natural radioactive decay of uranium in 1896 by Henry Becquerel, the French physicist, opened new vistas in every field of science. In 1905, the British physicist, Lord Rutherford-after defining the structure of the atom-made the first clear suggestion for using radioactivity as a tool for measuring geologic time directly; shortly thereafter, in 1907, Professor B. B. Boltwood, radiochemist of Yale University, published a list of geologic ages based on radioactivity. Although Boltwood's ages have since been revised, they did show correctly that the duration of geologic time would be measured in terms of hundreds-to-thousands of millions of years.

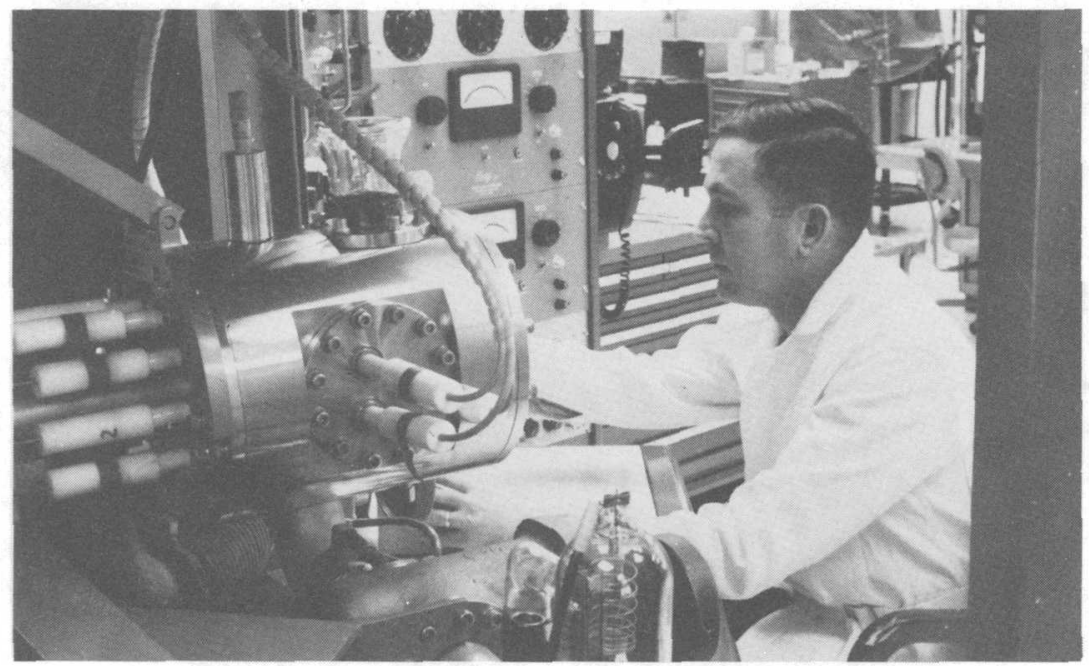

A physicist of the U. S. Geological Survey using a mass spectrometer to determine the amounts of uranium isotopes contained in a sample of rock.

The next 40 years was a period of expanding research on the nature and behavior of atoms, leading to the development of nuclear fission and fusion as energy sources. A byproduct of this atomic research has been the development and continuing refinement of the various methods and techniques used to measure the age of Earth materials. Most of the precise dating has been accomplished since 1950.

A chemical element consists of atoms with a specific number of protons in their nuclei but different atomic weights owing to variations in the number of neutrons. Atoms of the same element with differing atomic weights are called isotopes. Radioactive decay is a spontaneous process in which an isotope (the parent) loses particles from its nucleus to form an isotope of a new element (the daughter). The rate of decay is conveniently expressed in terms of 
an isotope's half-life, or the time it takes for one-half of the nuclei in a sample to decay. Most radioactive isotopes have rapid rates of decay (that is, short half-lives) and lose their radioactivity within a few days or years. Some isotopes, however, decay slowly and several of these are used as atomic clocks. The parent isotopes and corresponding daughter products most commonly used to determine the ages of ancient rocks are listed below:

$\begin{array}{lcc}\text { Parent Isotope } & \text { Stable Daughter Product } & \begin{array}{c}\text { Currently Accepted } \\ \text { Half-life Values }\end{array} \\ \text { Uranium-238 } & \text { Lead-206 } & 4.5 \text { billion years } \\ \text { Uranium-235 } & \text { Lead-207 } & 713 \text { million years } \\ \text { Thorium-232 } & \text { Lead-208 } & 14.1 \text { billion years } \\ \text { Rubidium-87 } & \text { Strontium-87 } & 50.0 \text { billion years } \\ \text { Potassium-40 } & \text { Argon-40 } & 1.3 \text { billion years }\end{array}$

The mathematical expression that relates radioactive decay to geologic time is called the age equation and is: $t=\frac{1}{\lambda} \cdot \ln \left(1+\frac{D}{P}\right)$

where $t$ is the age of a rock or mineral specimen,

$D$ is the number of atoms of a daughter product today,

$P$ is the number of atoms of the parent isotope today, in is the natural logarithm (logarithm to base e), and

$\lambda$ is the appropriate decay constant.

(The decay constant for each parent isotope is related to its half-life, $t \frac{1}{2}$, by the following expression: $t^{1 / 2}=\frac{2 n^{2}}{\lambda}$ )

Dating rocks by these radioactive timekeepers is simple in theory, but the laboratory procedures are complex. The numbers of parent and daughter isotopes in each specimen are determined by various kinds of analytical methods. The principal difficulty lies in measuring precisely very tiny amounts of isotopes.

At the present time, the potassium-argon method is one of the most useful dating techniques available to the geologist because it can be used on rocks as young as a few thousand years as well as on the oldest rocks known. Potassium is found in most rock-forming minerals, the half-life of its radioactive isotope potassium- 40 is such that measurable quantities of argon (daughter) have accumulated in potassium-bearing minerals of nearly all ages, and the amounts of potassium and argon isotopes can be measured accurately, even in very small quantities. Where feasible, two or more methods of analysis are used on the same specimen of rock to confirm the results.

Another important atomic clock used for dating purposes is based on the radioactive decay of the isotope carbon-14, which has a half-life of 5,730 years. Carbon-14 is produced continuously in the Earth's upper atmosphere as a result of nitrogen-14 isotopes 
being struck by neutrons that have their origin in cosmic rays. This newly formed radiocarbon becomes uniformly mixed with the nonradioactive carbon in the carbon dioxide of the air, and it eventually finds its way into all living plants and animals. In effect, all carbon in living organisms contains a constant proportion of radiocarbon. After the death of the organism, the amount of radiocarbon gradually decreases through radioactive decay as it reverts to nitrogen-14. By measuring the amount of radioactivity remaining in organic materials, the amount of carbon-14 in the materials can be calculated and the time of death can be determined. For example, if carbon from a sample of wood is found to contain only half as much carbon-14 as that from a living plant, the estimated age of the old wood would be 5,730 years.

The radiocarbon clock has become an extremely useful tool in dating the important episodes in the recent prehistory and history of man, but because of the relatively short half-life of carbon-14, the clock can be used for dating events that have taken place only within the past 50,000 years.

A sample of charcoal from the "Marmes Man" site in southeastern Washington being prepared for a carbon-14 age determination. The radiocarbon clock is an extremely useful tool in the study of prehistoric man.

Geologists processing a sample of carbon in a U. S. Geological Survey laboratory. The carbon is converted to a gas which is fed into proportional gas counters. The amount of $\mathrm{C}-14$ in the sample is then determined by measuring the radioactivity of the gas.
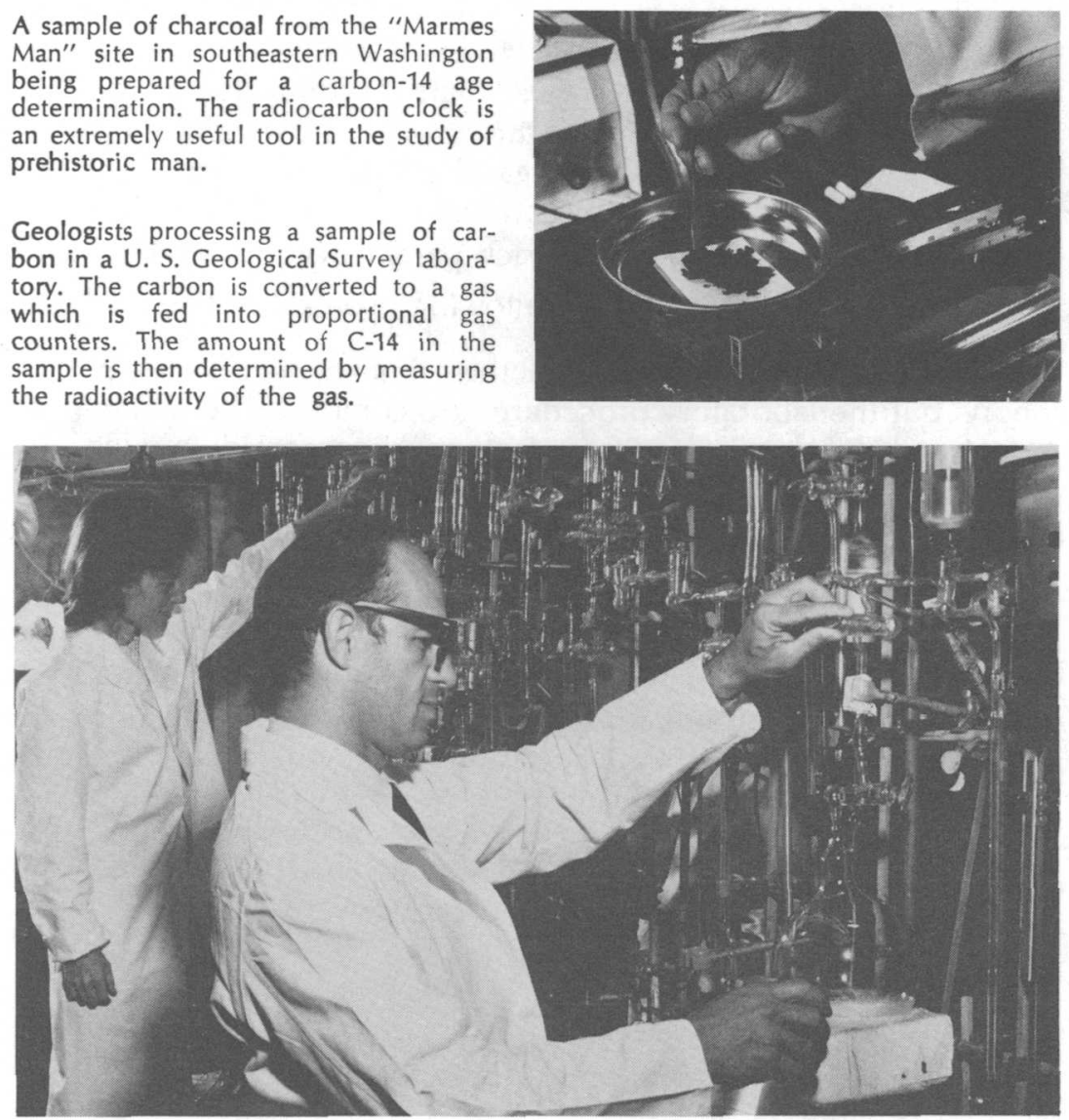
The following is a group of rocks and materials that have been dated by various atomic clock methods:

\section{Sample}

Cloth wrappings from a mummified bull

Samples taken from a pyramid in Dashur, Egypt. This date agrees with the age of the pyramid as estimated from historical records.

Charcoal.

Sample, recovered from bed of ash near Crater Lake, Oregon, is from a tree burned in the violent eruption of Mount Mazama which created Crater lake. This eruption blanketed several States with ash, providing geologists with an excellent time zone.

Charcoal.

Sample collected from the "Marmes Man" site in southeastern Washington. This rock shelter is believed to be among the oldest known inhabited sites in North America.

Tamarack tree fragment.

Sample, recovered from glacial debris near Green Bay, Wisconsin, dates the time of the last advance of the continental ice sheet into the United States from the north.

Bishop Tuff. 700,000

Samples collected from volcanic ash and pumice that overlie glacial debris in Owens Valley, California. This volcanic episode provides an important reference datum in the glacial history of North America.

Volcanic ash. $1,750,000$

Samples collected from strata in Olduvai Gorge, East Africa, which sandwich the fossil remains of Zinjanthropus and Homo Habilis- possible precursors of modern man.

Monzonite.

Samples of copper-bearing rock from vast open-pit mine at Bingham Canyon, Utah.

Quartz monzonite.

Samples collected from Half Dome, Yosemite National Park, California.

Conway Granite.

Samples collected from Redstone Quarry in the White Mountains of New Hampshire.

Rhyolite.

Samples collected from Mount Rogers, the highest point in Virginia.

Pikes Peak Ciranite.

Samples collected on top of Pikes Peak, Colorado.

Cineiss.

Samples from outcrops in the Karelian area of eastern Finland are believed to represent the oldest rocks in the Baltic region.

The Old Ciranite.

Samples from outcrops in the Transvaal, South Africa. These rocks intrude even older rocks that have not been dated.

Morton Gineiss.

$820,000,000$

Samples from outcrops in southwestern Minnesota are believed to represent the oldest rocks in North America. 
Interweaving the relative time scale with the atomic time scale poses certain problems because only certain types of rocks, chiefly the igneous variety, can be dated directly by atomic methods; but these rocks do not ordinarily contain fossils. Igneous rocks are those such as granite and basalt which crystallize from a molten state.

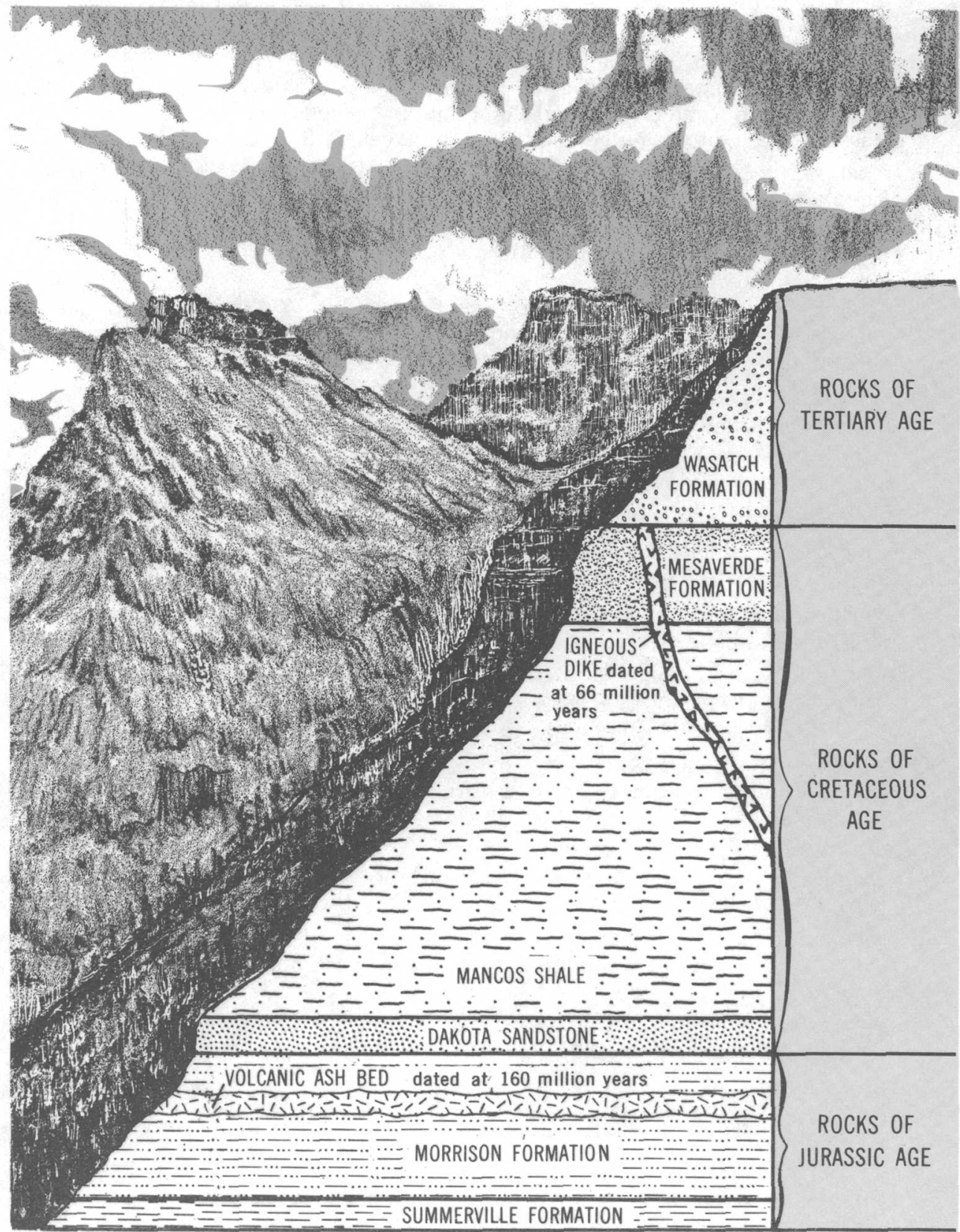


When igneous rocks crystallize, the newly formed minerals contain various amounts of chemical elements, some of which have radioactive isotopes. These isotopes decay within the rocks according to their half-life rates, and by selecting the appropriate minerals (those that contain potassium, for instance) and measuring the relative amounts of parent and daughter isotopes locked in them, the date at which the rock crystallized can be determined. Many of the large igneous rock masses of the world have been dated in this manner.

Most sedimentary rocks such as sandstone, limestone, and shale are related to the atomic time scale by bracketing them within time zones that are determined by dating appropriately selected igneous rocks, as shown in the hypothetical example on page 16.

The age of the volcanic ash bed and the igneous dike are determined directly by atomic clock methods. The layers of sedimentary rocks below the ash bed are obviously older than the ash, and all the layers above the ash are younger. The igneous dike is younger than the Mancos Shale and Mesaverde Formation but older than the Wasatch Formation because the dike does not intrude the Tertiary rocks.

From this kind of evidence, geologists estimate that the end of the Cretaceous Period and the beginning of the Tertiary Period took place between 60 and 70 million years ago. Similarly, a part of the Morrison Formation of Jurassic age was deposited about 160 million years ago as indicated by the age of the ash bed.

Literally thousands of dated materials are now available for use to bracket the various episodes in the history of the Earth within specific time zones. Many points on the time scale are being revised, however, as the behavior of isotopes in the Earth's crust is more clearly understood. Thus the graphic illustration of the geologic time scale, showing both relative time and atomic time, represents only the present state of knowledge. Certainly, revisions and modifications will be forthcoming as research continues to improve our knowledge of Earth history.

\section{THE AGE of the EARTH}

The oldest known formation in North America, the Morton Gneiss of Minnesota, appears to have formed about $3 \frac{1}{2}$ billion years ago. Other rocks of similar or somewhat younger age occur in South Africa, Finland, Australia, and elsewhere. Upon what evidence is a minimum age for the Earth of $4 \frac{1}{2}$ billion years based?

Some estimates of the age of the Earth are based on the decay rates of radioactive isotopes. One such estimate is based on two long-lived isotopes, uranium-238 and uranium-235, and places the 


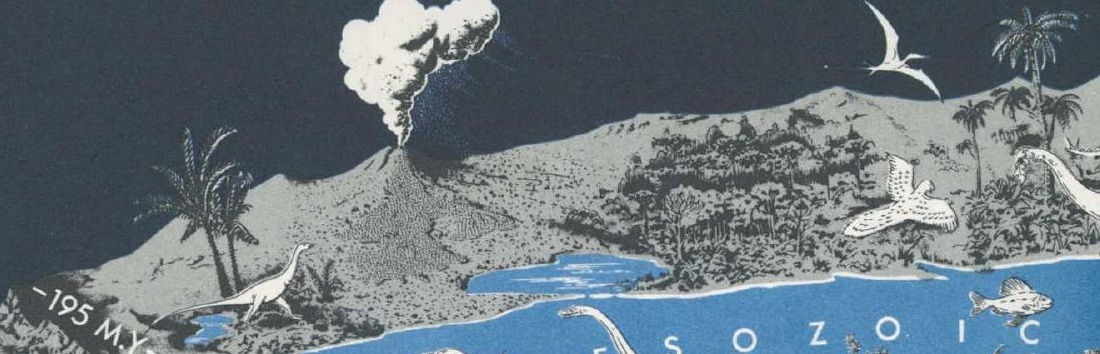

$x_{-1}=2$

$25 \mathrm{MLL}+10 \mathrm{~N}$

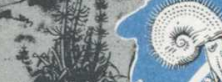

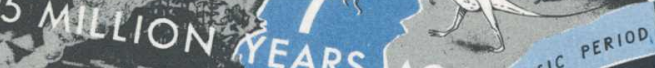

$+0=-7$ TEARS AGO

$\left.x_{x \rightarrow 3} x\right\}$

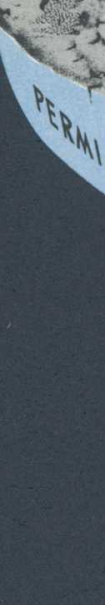

4 t

4

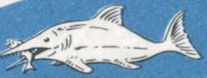

E

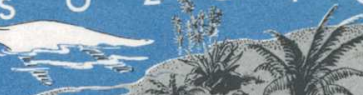

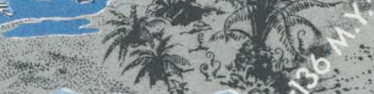

ELATIVE AND ATOMIC GEOLOGIC TIME

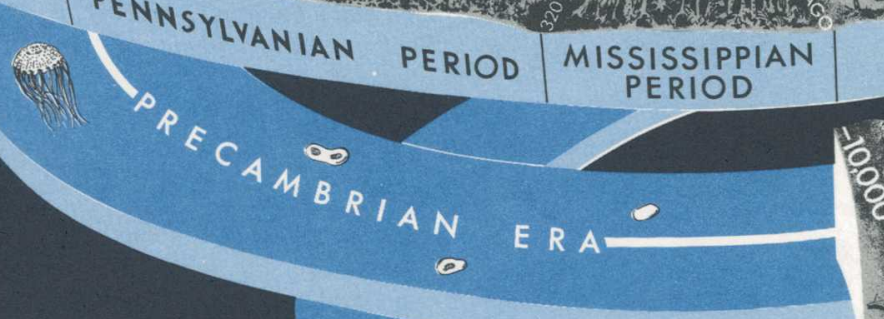
PENNSYLVANIAN PERIOD
PISSISSIPPIAN
PERIOD

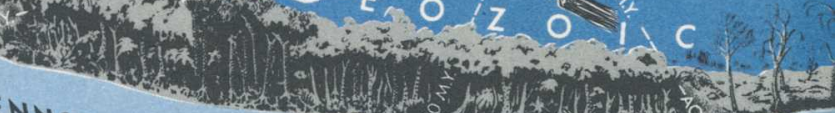


maximum age of the chemical elements that make up the Earth at about 6 billion years. The reasoning behind this estimate involves theoretical concepts about the origin of uranium which stipulate that not more than half the first-formed uranium consisted of the uranium-235 isotope. But, because of the changes in isotopic composition that have taken place throughout geologic time as a result of radioactive decay, uranium today contains only about 0.7 percent of the uranium-235 isotope. Calculations based on the known decay rates for these two isotopes (table, page 13) indicate that a span of about 6 billion years is required for the isotopic composition of uranium to have changed from 50 percent to 0.7 percent uranium-235. Had uranium originally consisted of more than half of the uranium-235 isotope, the calculated age of uranium would exceed 6 billion years.

Another estimate of the Earth's age is based on the progressive buildup in the Earth's crust of lead isotopes that have been derived from radioactive decay of uranium-238, uranium-235, and thorium232. Studies of the relative abundance of these "radiogenic" leads suggest that the Earth is not older than 5.5 billion years.

In the past 10 years, an approximate age for the Earth has been determined from studies of meteorites. Meteorites are specimens of matter from space; they are classified according to their chemical composition into three main groups: the irons, the stoney irons, and the stones. Because of chemical similarities between meteorites and the rocks of the Earth (these three groups may correspond to the three major parts of the Earth-the core, the mantle, and the crust), it is generally assumed that meteorites and the Earth have a common origin and were formed as soilid objects at about the same time during the evolution of the Solar System. Thus, what can be learned from meteorites can be used to interpret the Earth. Chemical analyses of iron meteorites show that the uranium content is so low that the isotopic composition of lead has not been changed significantly by the addition of radiogenic lead since the formation of the meteorites. Thus, the lead in iron meteorites is considered to be primordial lead. Stony meteorites, however, contain sufficient uranium to have produced appreciable quantities of radiogenic lead since the meteorites were formed. When the measured amounts of radiogenic lead in stony meteorites are corrected by subtracting the amount of primordial lead in iron meteorites, calculations yield an age of about $4 \frac{1}{2}$ billion years for stony meteorites. If the Earth and meteorites have a common or a similar origin, then it seems reasonable to assume that the age of the Earth is about the same as the age of the meteorites.

Thus, as a current working hypothesis based on several kinds of evidence, geologists consider the Earth to be about 41/2 billion years old.

By William L. Newman 
As the Nation's principal conservation agency, the Department of the Interior has responsibility for most of our nationally owned public lands and natural resources. This includes fostering the wisest use of our land and water resources, protecting our fish and wildlife, preserving the environmental and cultural values of our national parks and historical places, and providing for the enjoyment of life through outdoor recreation. The Department assesses our. energy and mineral resources and works to assure that their development is in the best interests of all our people. The Department also has a major responsibility for American Indian reservation communities and for people who live in Island Territories under U.S. administration.

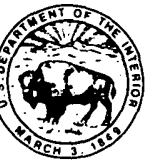

Cecil D. Andrus, Secretary

U.S. Department of the Interior

V.E. McKelvey, Director

Geological Survey
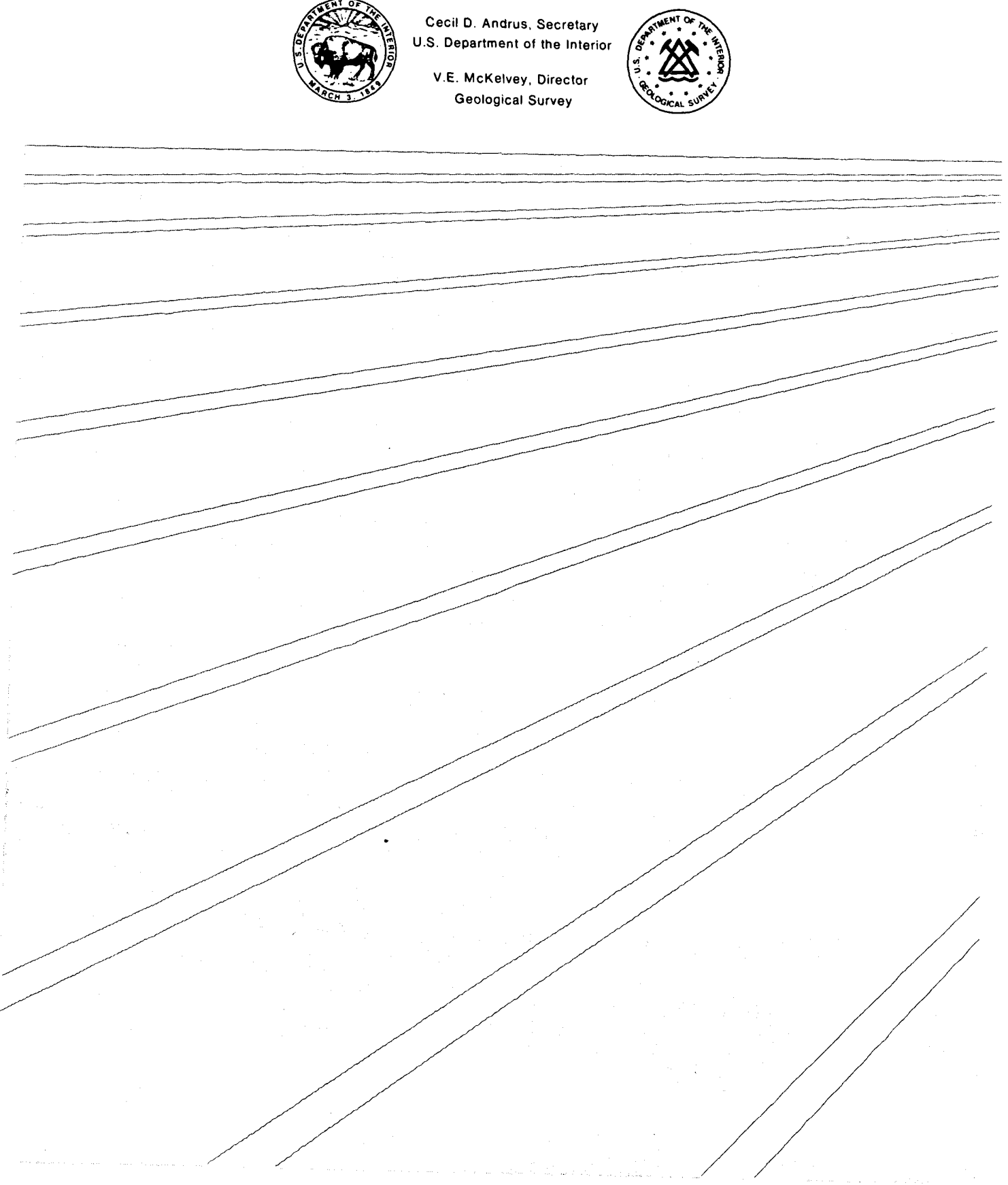